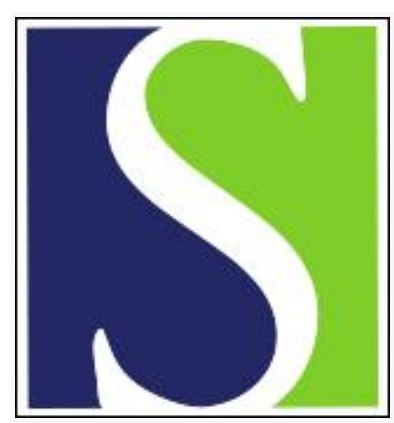

Scand J Work Environ Health 1986;12(4):254-258

https://doi.org/10.5271/sjweh.2142

Issue date: Aug 1986

Cold provocation tests in the evaluation of vibration-induced white finger.

by Pyykko I, Farkkila M, Korhonen O, Starck J, Jantti V

This article in PubMed: www.ncbi.nlm.nih.gov/pubmed/3775310

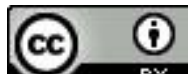




\title{
Cold provocation tests in the evaluation of vibration-induced white finger
}

\author{
by llmari Pyykkö, MD, ${ }^{1}$ Markus Färkkilä, MD, ${ }^{2}$ Olli Korhonen, MD, ${ }^{1}$ Jukka Starck, PhD, ${ }^{1}$ \\ Ville Jäntti, $M D^{3}$
}

\begin{abstract}
PYYKKÖ I, FÄRKKILÄ M, KORHONEN O, STARCK J, JÄNTTI V. Cold provocation tests in the evaluation of vibration-induced white finger. Scand $J$ Work Environ Health 12 (1986) 254-258. Two types of cold provocation tests, a classical test with immersion of the hand in cold water and the evaluation of finger systolic blood pressure (FSBP) during local cooling, were administered to forest workers. Raynaud's phenomenon in the classical test correlated positively with the number of disabled phalanges, recovery time, and frequency of attacks. It did not correlate with the severity of paresthesia of the hands and arms. Repetition of the test enhanced the number of positive results. A significant reduction in the FSBP was observed in 22 and $25 \%$ of the subjects with inactive and active forms of vibration-induced white finger (VWF), respectively. In the same groups of subjects the classical cold provocation test yielded positive results in 7 and $25 \%$ of the subjects, respectively. A cold provocation test was found to produce a positive result even some years after the cessation of VWF attacks. The rather low severity of VWF among the examined subjects may explain the lack of positive test results. FSBP measurement was not superior to cold provocation by water immersion, but it is recommended because it is easier to standardize and more convenient for the test subject.
\end{abstract}

Key terms: local finger cooling, Raynaud's phenomenon, systolic blood pressure of the finger, water immersion of the hands.

The spontaneous character of vibration-induced white finger (VWF) causes a remarkable variation in the extent of accompanying symptoms, depending, for example, on the season of the year, the occupation of the subject, the ambient temperature, and the mode of transportation $(15,19)$. Because the vascular symptoms are provoked by exposure to environmental cold, various cold provocation tests have been used for diagnostic purposes. Some researchers have measured the recovery time for the temperature of the fingers (2), whereas some have observed changes in the finger systolic blood pressure (FSBP) $(7,10,12,20)$ or have visually inspected the appearance of Raynaud's phenomenon $(8,19)$.

Some controversy exists as to the validity of the different tests used for diagnosing VWF. Nielsen \& Lassen (11), Olsen \& Nielsen (12), and Thulesius et al (20), among others, showed that the sensitivity of FSBP measurements is high for VWF. A correct diagnosis of VWF could be ascertained in about $70 \%$ of the cases. Ekenvall \& Lindblad (3) compared digital rewarming time and FSBP in the same forest workers. They observed that rewarming time could be prolonged even in a symptom-free subject and proposed that this time correlated to the length of exposure to vibration

\footnotetext{
1 Institute of Occupational Health, Helsinki, Finland.

2 Department of Neurology, Helsinki University Central Hospital, Helsinki, Finland.

3 Department of Clinical Neurophysiology, Tampere University Central Hospital, Tampere, Finland.
}

Reprint requests to: Dr I Pyykkö, Institute of Occupational Health, Topeliuksenkatu 41 a A, SF-00250 Finland. and that FSBP-recorded vascular changes were related to VWF. The "classical" cold provocation test, in which the upper body is cooled and the hands are immersed in cold water for $10 \mathrm{~min}$, has an apparently low sensitivity (19). However, the specificity of this test is high.

The purpose of the present study was to evaluate the validity of two cold provocation tests (measurement of FSBP during local cooling and the aforementioned "classical" cold provocation test) in the diagnosis of VWF in a group of forest workers and compare the results of the two tests.

\section{Subjects and methods}

A longitudinal investigation was carried out during the winters of 1972-1981 and 1983 in connection with a compulsory health examination of the same group of forest workers in northern Finland. Most of the forest workers working under the National Board of Forestry in one municipal district was examined. Workers who had used a chain saw for at least three consecutive years with a minimum of $500 \mathrm{~h}$ of use per year were included in the study. The age distribution and number of forest workers studied in the years 1972, 1975, and 1983 are shown in table 1. Due to reorganization an increase occurred in the number of forest workers in 1975.

A classical cold provocation test was carried out in 1972-1981 and in 1983. The temperature of the testing room was kept at $18-22^{\circ} \mathrm{C}$. The subjects submerged their arms up to their shoulders in water, the 
temperature of which was kept between $12-15^{\circ} \mathrm{C}$, and squeezed metal cylinders in their hands. A cold towel, wrung out of cold water $\left(12-15^{\circ} \mathrm{C}\right)$, was laid on their bare shoulders. Every $15 \mathrm{~s}$ the towel was changed. After $10 \mathrm{~min}$ alterations in the color of the skin were observed. If the color of at least one phalanx of a finger remained white for longer than $1 \mathrm{~min}$, a positive sign of Raynaud's phenomenon was recorded. Small, patchy whitenings, often seen after a cold provocation test, or blue skin color was excluded.

From the 206 forest workers examined in 1983, all workers with a history of VWF and a symptom-free group were studied with an additional strain-gauge plethysmography technique for the measurement of FSBP. The total number of examined workers was $60-21$ workers free of any symptoms associated with VWF (the reference group); 27 workers with a history of VWF but without any signs of VWF during the last two years (the inactive VWF group), and 12 workers still experiencing attacks of VWF within the last two years (the active VWF group). Workers with other reasons for Raynaud's phenomenon were excluded from the analysis. These reasons were primary Raynaud's disease (six subjects), traumatic hand injuries (three subjects), and thoracic outlet syndrome (one subject). The mean age of the subjects and their mean length of exposure to vibration are shown in table 2 . The comparison between the two types of cold provocation tests (classical cold provocation and FSBP measurement) was made from the results of these 60 workers.

Strain-gauge plethysmography (Medimatic SP2) with a digital cooling cuff was used for the evaluation of FSBP (figure 1). Before the test the hand was warmed with hot water $\left(42^{\circ} \mathrm{C}\right)$. After the recording of the base-line values, the most affected finger was cooled to $20,15,10$, and $5^{\circ} \mathrm{C}$ for $5 \mathrm{~min}$. Blood circulation was stopped for $5 \mathrm{~min}$ during the cooling period with suprasystolic pressure of $250 \mathrm{~mm} \mathrm{Hg}$ (33 $331 \mathrm{~Pa}$ ). The interval between the successive coolings was $5 \mathrm{~min}$. For standardization of the results, the following formula was used: $\%$ pressure $=100[(\mathrm{Pc30}$ - Pt)/(P30 - Pct)], in which $\mathrm{Pc30}$ is the systolic pressure of the control finger at $30^{\circ} \mathrm{C}$, Pct is the systolic pressure of the control finger at cooling temperature $\mathrm{t}$, and $\mathrm{P} 30$ and $\mathrm{Pt}$ are the respective values of the cooled finger.

The correlation ( $r$ ) between the cold provocation tests and the different variables of VWF were studied in a linear regression analysis. Student's t-test was used in the evaluation of the blood pressure in the arm between the groups. The repeatability of the cold provocation tests was studied with the chi-square test. The diagnostic accuracy of the classical cold provocation test in comparison with that of the strain-gauge plethysmography was evaluated with the KolmogorovSmirnov test. When the probability (p) was less than 0.05 , the difference was considered to be statistically significant (NS = not significant).

\section{Results}

Classical cold provocation test of subjects with a history of vibration-induced white finger in the longitudinal study

Situation in 1972. The prevalence of active VWF reported by the forest workers in the longitudinal study was $40 \%$ in 1972. (See references 15 and 19.) A positive result in the classical cold provocation test was observed in $52 \%$ of these subjects. In the assessment of the relationship between the cold provocation test and various factors among 47 forest workers with active VWF, a statistically significant correlation was found between the cold provocation test and the number of affected phalanges $(r=0.292, p<0.01)$, recovery from the attack $(r=0.374, p<0.01)$, and the frequency of the attack $(r=0.374, p<0.01)$. We found no correlation between the cold provocation test and paresthesias in the hands and arms ( $r=0.105, p$ NS).

Table 1. Age distribution of the forest workers studied in different years of the longitudinal investigation.

\begin{tabular}{lrcr}
\hline \multirow{2}{*}{$\begin{array}{l}\text { Age } \\
\text { (years) }\end{array}$} & \multicolumn{3}{c}{ Year of examination } \\
\cline { 2 - 4 } & 1972 & 1975 & 1983 \\
\hline $20-29$ & 32 & 45 & 31 \\
$30-39$ & 48 & 57 & 65 \\
$40-49$ & 34 & 76 & 67 \\
$50-59$ & 4 & 9 & 43 \\
\hline Total & 118 & 187 & 206 \\
\hline
\end{tabular}

Table 2. Age of the three groups of workers given both the classical cold provocation test and the measurement of finger systolic blood pressure and their duration of exposure to chainsaw vibration. (VWF = vibration-induced white finger)

\begin{tabular}{|c|c|c|c|c|c|}
\hline \multirow{2}{*}{ Group } & \multirow{2}{*}{$\begin{array}{c}\text { Number } \\
\text { of } \\
\text { subjects }\end{array}$} & \multicolumn{2}{|c|}{ Age (years) } & \multicolumn{2}{|c|}{ Exposure (h) } \\
\hline & & Mean & SD & Mean & SO \\
\hline $\begin{array}{l}\text { Active VWF } \\
\text { Inactive VWF } \\
\text { Reference }\end{array}$ & $\begin{array}{l}12 \\
27 \\
21\end{array}$ & $\begin{array}{l}47.1 \\
49.7 \\
45.4\end{array}$ & $\begin{array}{l}7.5 \\
5.8 \\
7.4\end{array}$ & $\begin{array}{l}130700 \\
168500 \\
164000\end{array}$ & $\begin{array}{l}77 \\
63 \\
50\end{array}$ \\
\hline
\end{tabular}

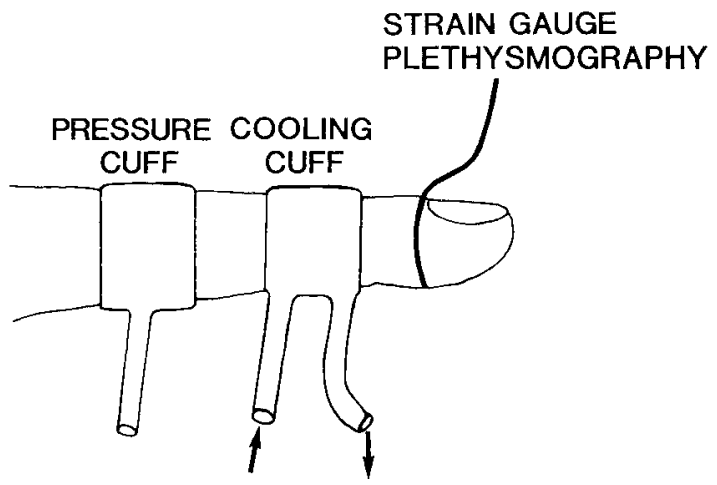

Figure 1. Position of finger cuffs during measurement of finger systolic blood pressure. 

Table 3. Results of the classical cold provocation test when conducted twice during the same day with an interval of either
2,4 , or $6 \mathrm{~h}$.

\begin{tabular}{|c|c|c|c|c|c|c|c|c|c|c|c|}
\hline \multirow{3}{*}{$\begin{array}{l}\text { Test } \\
\text { interval }\end{array}$} & \multirow{3}{*}{$\begin{array}{l}\text { Number of } \\
\text { subjects }\end{array}$} & \multicolumn{4}{|c|}{$\begin{array}{l}\text { Number of phalanges with } \\
\text { Raynaud's phenomenon }\end{array}$} & \multicolumn{4}{|c|}{$\begin{array}{l}\text { Duration of Raynaud's } \\
\text { phenomenon (min) }\end{array}$} & \multirow{2}{*}{\multicolumn{2}{|c|}{$\begin{array}{l}\text { TVD index } \\
\text { score }\end{array}$}} \\
\hline & & \multicolumn{2}{|c|}{ Test 1} & \multicolumn{2}{|c|}{ Test 2} & \multicolumn{2}{|c|}{ Test 1} & \multicolumn{2}{|c|}{ Test 2} & & \\
\hline & & Mean & SD & Mean & SD & Mean & SD & Mean & SD & Mean & SD \\
\hline $\begin{array}{l}2 \mathrm{~h} \\
4 \mathrm{~h} \\
6 \mathrm{~h}\end{array}$ & $\begin{array}{l}17 \\
25 \\
25\end{array}$ & $\begin{array}{l}5.0 \\
3.7 \\
1.4\end{array}$ & $\begin{array}{l}7.6 \\
6.5 \\
3.0\end{array}$ & $\begin{array}{l}4.5 \\
4.0 \\
4.7\end{array}$ & $\begin{array}{l}6.1 \\
4.4 \\
6.6\end{array}$ & $\begin{array}{r}12.5 \\
6.5 \\
1.9\end{array}$ & $\begin{array}{r}18.9 \\
10.4 \\
3.8\end{array}$ & $\begin{array}{r}8.4 \\
8.2 \\
11.3\end{array}$ & $\begin{array}{l}11.9 \\
12.8 \\
22.7\end{array}$ & $\begin{array}{l}1.0 \\
1.0 \\
1.0\end{array}$ & $\begin{array}{l}0.9 \\
0.9 \\
0.7\end{array}$ \\
\hline
\end{tabular}

Table 4. Systolic and diastolic blood pressure $\left(\mathrm{mm} \mathrm{Hg}^{2}\right)$ measured in the arms of the subjects in the three groups of forest workers. (VWF = vibration-induced white finger)

\begin{tabular}{|c|c|c|c|c|c|c|c|c|c|}
\hline \multirow{3}{*}{ Group } & \multirow{3}{*}{$\begin{array}{l}\text { Number } \\
\text { of } \\
\text { subjects }\end{array}$} & \multicolumn{4}{|c|}{ Before test } & \multicolumn{4}{|c|}{ After test } \\
\hline & & \multicolumn{2}{|c|}{ Systolic } & \multicolumn{2}{|c|}{ Diastolic } & \multicolumn{2}{|c|}{ Systolic } & \multicolumn{2}{|c|}{ Diastolic } \\
\hline & & Mean & SD & Mean & SD & Mean & SD & Mean & SD \\
\hline $\begin{array}{l}\text { Active VWF } \\
\text { Inactive VWF } \\
\text { Reference }\end{array}$ & $\begin{array}{l}12 \\
27 \\
21\end{array}$ & $\begin{array}{l}137.3 \\
137.7 \\
130.7\end{array}$ & $\begin{array}{l}14.7 \\
12.6^{*} \\
12.8\end{array}$ & $\begin{array}{l}83.2 \\
81.8 \\
80.6\end{array}$ & $\begin{array}{r}14.7 \\
10.9 \\
8.1\end{array}$ & $\begin{array}{l}140.0 \\
140.3 \\
120.0\end{array}$ & $\begin{array}{l}14.1^{\star} \\
12.6^{\star} \\
11.6\end{array}$ & $\begin{array}{l}86.4 \\
87.8 \\
81.9\end{array}$ & $\begin{array}{l}6.7^{* \star} \\
9.5^{\star} \\
8.9\end{array}$ \\
\hline
\end{tabular}

a $1 \mathrm{~mm} \mathrm{Hg} \approx 133.322 \mathrm{~Pa}$.

${ }^{*} p<0.01,{ }^{*} p<0.001$ (versus values of the reference group).

Situation in 1975. The prevalence of active VWF among the forest workers had decreased to $25 \%$ in 1975. (See references 18 and 19.) A positive result in the classical cold provocation test was observed in $45 \%$ of the subjects. The repeatability of the test was studied among 64 forest workers. Tests were conducted twice at intervals of 2,4 , and $6 \mathrm{~h}$. The results were evaluated qualitatively and quantitatively by the estimation of the number of affected phalanges and recovery time for each test (table 3). An interval of $6 \mathrm{~h}$ seemed to yield a positive result more often $(\mathrm{t}(22)=$ $2.13, \mathrm{p}<0.05$ ).

When the results of the tests at different intervals were pooled, the first test produced a positive result in 28 of the 64 forest workers with a history of VWF $(45 \%)$. In the second test the corresponding figure was $37(58 \%)$. There was no statistically significant difference in the number of occurrences of Raynaud's phenomenon between the first and second test $\left(\chi^{2}(1)\right.$ $=2.00, \mathrm{p} \mathrm{NS}$ ). It is noteworthy that the subjects with a positive result in one test could respond negatively in the other. When the results of all the tests were combined, a positive finding was recorded for 43 of the 64 subjects $(67 \%)$; this figure was statistically significant $\left(\chi^{2}(1)=5.83, \mathrm{p}<0.02\right)$.

Situation in 1983. The prevalence of active VWF among the forest workers had decreased to $5 \%$ in 1983. (See reference 19.) In the classical cold provocation test, a positive result was observed in $25 \%$ of the subjects.
Classical cold provocation test of subjects without a history of vibration-induced white finger in the longitudinal study

Workers not affected by VWF were randomly sampled in the different years of the longitudinal study, and three positive results were recorded for the 44 tests performed. One subject had a traumatic denervation in the affected finger, one had suffered from frostbite, and one subject presumably had a false positive result.

\section{Finger systolic blood pressure during cold provocation}

The mean systolic and diastolic blood pressure as measured in the arm by auscultation tended be lower in the forest workers without VWF than in those with active or inactive VWF (table 4).

During local cooling of the finger at different temperatures the mean standardized FSBP did not differ significantly between the inactive VWF group and the reference group (figure 2 ). The subjects with active VWF had a significantly lower FSBP than the reference group at local temperatures of 15,10 , and $5^{\circ} \mathrm{C}$.

The accuracy of the FSBP measurement in the diagnosis of VWF at the different temperatures is shown in table 5 . The accuracy increased as the temperature decreased, and it was highest at $5^{\circ} \mathrm{C}$.

\section{Comparison of the two types of cold provocation tests}

In the classical cold provocation test, 3 of the 12 subjects with active VWF had Raynaud's phenomenon, and the respective figures for the inactive VWF group were 2 of 27 subjects. Thus, in the active VWF group, 
the same percentage of subjects reacted positively in the classical and FSBP (table 5) cold provocation tests. In the inactive VWF group, the number of pathological results in the FSBP measurements tended to be greater than the observed frequency of Raynaud's phenomenon in the classical test. The difference between these two tests was not, however, statistically significant.

Three subjects had a positive result for VWF in both tests. Two of the three were from the active VWF group, and one was from the inactive VWF group.

\section{Discussion}

Since the physiological studies of Lewis \& Pickering (9) cold provocation tests with different modifications have been used to assess vibration-induced vascular disturbances. However, in only a few studies have different cooling tests been compared. In the present study, a cold provocation test by immersion of the hands in cold water and FSBP measurement during local cooling of the finger were investigated. Both tests were conducted under field conditions and with the same group of forest workers. Neither test proved to be superior in revealing VWF among forest workers. Thus, in tests in which Raynaud's phenomenon is detected by visual inspection or even by FSBP measurement, a negative result does not exclude the possibility of VWF. Furthermore, the results of a cold provocation test can vary in repeated tests with the same individual.

A cold provocation test combined with the evaluation of FSBP measurements made with strain-gauge plethysmography may be easier to standardize than a cold provocation test with immersion of the hands in cold water. Several reports have confirmed that the measurement of FSBP can detect some 60 to $85 \%$ of workers affected by VWF $(13,21)$. In the classical cold provocation test, positive results of between 40 and $95 \%$ have been reported for subjects with VWF. (For a review, see reference 18 .)

In the evaluation of VWF with FSBP measurements, proper use of the technique is required. Several cooling temperatures ranging from 30 to $5^{\circ} \mathrm{C}$ have been recommended (10). Nevertheless, the lowest temperature $\left(+5^{\circ} \mathrm{C}\right)$ usually discriminates best between workers with and those without VWF $(12,20)$, as was also observed in the present study. If the upper body is cooled simultaneously, the accuracy of the test increases $(1,11)$. In the present study, as in most similar studies, two different cuffs were used, one for pressure and one for cooling. It is claimed that, if the cooling cuff has the same pressure as the pressure cuff, the sensitivity will be better (11, Ekenval personal communication). Individual laboratories seem to have some modifications in the basic technique of the test $(6,20)$. Therefore, each laboratory should establish its own norms. It should be noted, however, that, in our experience and that of others (Ekenval and Thulesius,

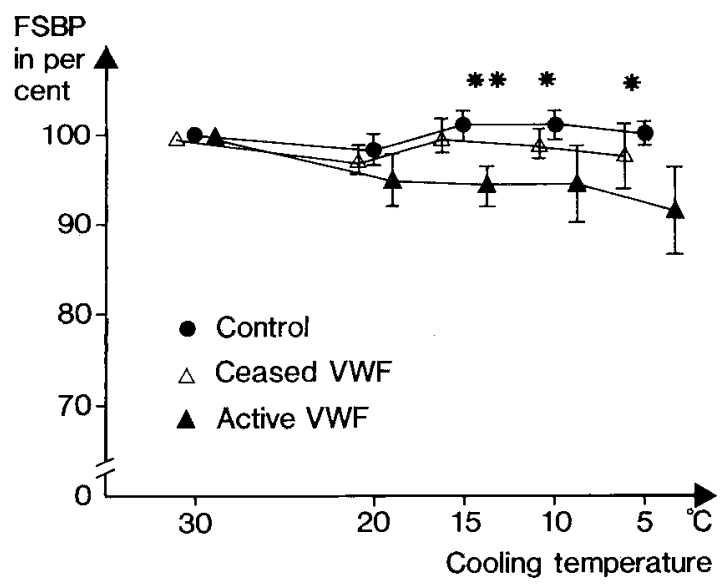

Figure 2. Means and standard errors of the means of the finger systolic blood pressure (FSBP) in the active VWF, the inactive (ceased) VWF, and the reference (control) groups of forest workers $\left({ }^{*} p<0.05,{ }^{*} p<0.01\right.$ ). (VWF $=$ vibration-induced white finger)

Table 5. Percentage of positive results in the measurement of finger systolic blood pressure at the different temperatures used in the study. The $95 \%$ confidence limit was used as the normative value. (VWF = vibration-induced white finger)

\begin{tabular}{lcrrrr}
\hline \multirow{2}{*}{ Group } & $\begin{array}{c}\text { Number } \\
\text { of } \\
\text { subjects }\end{array}$ & $20^{\circ} \mathrm{C}$ & $15^{\circ} \mathrm{C}$ & $10^{\circ} \mathrm{C}$ & $5^{\circ} \mathrm{C}$ \\
\cline { 3 - 6 } Active VWF & 25 & 25 & 25 & 25 & 25 \\
Inactive VWF & 27 & 4 & 7 & 7 & 22 \\
Reference & 21 & 5 & 5 & 5 & 5 \\
\hline
\end{tabular}

personal communication), none of the cold provocation tests seem to work satisfactorily in the summer, and therefore some seasonal variation in the tests cannot be avoided.

In cold provocation tests with plethysmography, cases with low severity and only occasional attacks of VWF tend to remain undetected, as was also experienced in the present study. In other studies, however, Olsen \& Nielsen (12) and Voss et al (21) indicated that FSBP measurement could predict about $70 \%$ of the subjects with VWF without the history of VWF being known. They, however, examined workers with a higher severity of VWF (Taylor's index 2 or 3) than was the case in the present study. This difference in severity may explain the differences in the sensitivity of the test between the present study and the previous investigations. In cases with negative results the extent of the disease was, in general, mild (15).

Recently we have found indications that, in subjects with VWF, flow reduction precedes pressure reduction in the cold provocation test $(5,16,17)$. Thus, an evaluation of flow or, preferably, variables linked to peripheral resistance might add to the diagnostic accuracy.

The sensitivity of cold provocation tests under field conditions is possibly not as good as it might be if the 
tests were conducted under laboratory conditions. For example, in the laboratory, cooling of the examining room may facilitate the number of positive tests by increasing the general tone of the autonomic nervous system $(4,11)$. In addition manually emptying the veins and arteries of the finger during the cold provocation increases the number of positive results (20). Of note is the fact that the low sensitivity of the tests in the present study presumably depended on the fact that the severity of VWF has been declining among the group of forest workers tested $(14,15)$. Since the number of postive tests significantly correlates with the extent of blanching of the fingers, a low sensitivity score can be observed in mild cases. It must be stressed that, in the present study, the severity of VWF was reduced along with the prevalence of VWF. Since 1975 the forest workers had primarily had mild VWF corresponding to Taylor's stage 1 . Thus the present results probably underestimate the real sensitivity of these tests among workers with VWF of different stages of severity.

\section{Conclusions}

In the present study the classical cold provocation test and FSBP measurement during local cooling had about the same sensitivity in discriminating between cases with and those without VWF. The low sensitivity probably resulted from the low severity of VWF among the forest workers examined. Both tests showed a good specificity. Since strain-gauge plethysmography is, however, more convenient for the subject than immersion of the hands in cold water, it should be preferred for the clinical evaluation of VWF.

\section{References}

1. Arneklo-Nobin B. The white cold hand. University of Lund, Lund 1983. (Bulletin no 37 from the Department of Surgery). (Doctoral dissertation).

2. Bovenzi M, Petronio L, Di Marino F. Epidemiological survey of shipyard workers exposed to hand-arm vibration. Int Arch Occup Environ Health 46 (1980) $251-266$.

3. Ekenvall L, Lindblad L-E. Digital blood pressure after local cooling as a diagnostic tool in traumatic vasospastic disease. Br J Ind Med 39 (1982) 388-391.

4. Gaskell P, Krisman AM. Critical closing pressure of vessels supplying the capillary loops of the nailfold. Circ Res 6 (1958) 461-467.
5. Gemne G, Pyykkö I, Starck J, Ilmarinen R. Circulatory reaction to heat and cold in vibration-induced white finger with and without sympathetic blockade An experimental study. Scand J Work Environ Health 12 (1986) $371-377$.

6. Hirai M, Nielsen SL, Lassen NA. Blood pressure measurements of all five fingers by strain gauge plethysmography. Scand J Clin Lab Invest 36 (1976) 627-632.

7. Jepson RP. The effects of vascular occlusion and local cooling on finger skin blood flow. Clin Sci 13 (1954) $259-265$.

8. Lewis T. Experiments relating to the peripheral mechanism involved in spasmodic arrest of the circulation in the fingers, a variety of Raynaud's disease. Heart 15 (1929) 7-101.

9. Lewis T, Pickering GW. Observations upon maladies in which the blood supply to digits ceases intermittently or permanently, and upon bilateral gangrane of digits; observations relevant to so-called "Raynaud's disease." Clin Sci 1 (1934) 327-366.

10. Nielsen SL. Raynaud's phenomena and finger systolic pressure during cooling. Scand J Clin Lab Invest 38 (1978) 765-770.

11. Nielsen SL, Lassen NA. Measurement of digital blood pressure after local cooling. J Appl Physiol 43 (1977) 907-910.

12. Olsen N, Nielsen SL. Diagnosis of Raynaud's phenomenon in quarrymen's traumatic vasospastic disease. Scand J Work Environ Health 5 (1979) 249-256.

13. Olsen N, Nielsen SL, Voss P. Cold response of digital arteries in chain saw operators. $\mathrm{Br} J$ Ind Med 39 (1982) 82-88.

14. Pyykkö I. The hand-arm vibration syndrome: Definitions and assessment of symptoms. J Low Freq Noise Vibr 1 (1983): special issue, 6-8.

15. Pyykkö I. The prevalence and symptoms of traumatic vasospastic disease among lumberjacks in Finland: A field study. Work Environ Health 11 (1974) 118-131.

16. Pyykkö 1 . Clinical aspects of the hand-arm vibration syndrome. Scand J Work Environ Health 12 (1986) (in press).

17. Pyykkö I, Kolari P, Färkkilä M, Starck J, Korhonen O Jäntti V. Finger peripheral resistance during local cold provocation in vasospastic disease. Scand J Work Environ Health 12 (1986) 395-399.

18. Pyykkö I, Korhonen OS, Färkkilä MA, Starck JP, Aatola SA. Longitudinal study of the vibration syndrome in Finnish forestry workers. In: Brammer AJ, Taylor $W$, ed. Vibration effects on the hand and arm in industry, John Wiley \& Sons, New York, NY 1982, pp $157-167$.

19. Pyykkö I, Korhonen O, Färkkilä M, Starck J, Aatola $S$. Vibration syndrome among Finnish forest workers: A follow-up. Scand J Work Environ Health 12 (1986) $307-312$.

20. Thulesius O, Brubaker A, Berlin E. Response of digital blood pressure to cold provocation in cases with Raynaud's phenomenon. Angiologia 32 (1981) 113-118.

21. Voss $\mathrm{P}$, Olsen $\mathrm{N}$, Nielsen SL. Vibrationsskader fra håndvärketöjer. Lydteknik, Teknologisk Institut, Tåstrup (Denmark) 1979. (Hovedrapport). 